\title{
Oral Narrative an Underutilized Tool of Transformation: The Case of Ateso Folk Tales in Iteso Communities of Uganda and Kenya*
}

\author{
Simon Peter Ongodia \\ Makerere University, Kampala, Uganda
}

\begin{abstract}
The study explored the various performances of oral narratives in the Teso communities. In-depth interviews carried out with 68 respondents from 2009 to 2013, in six selected Teso districts in Uganda and Teso and Busia districts in Kenya, before and after performances, provided the data. In placing value and assessing the unquantifiable feelings of narrators and audiences, the study chose the methods of qualitative research and ethno-methodological philosophical analyses. Various levels of perceptions emerged from both the audiences and performers as they journeyed into both self and society. The study showed that the communities yearned for the communicative avenues of harnessing resources for solving various issues as they look into the future. Oral narratives motivated audiences through experiences of self discovery which spurred them to analogies of societal issues that haunted them. Both value and virtue were experienced at individual and group levels with a cultural identity and exposure to ethnic ties that bound them together in the struggle for a brighter tomorrow. The study recommends that a new society can be realized with movement from analogue to digital strategies for communication.
\end{abstract}

Keywords: Ateso, Iteso, folklore, narrative, self-discovery, analogue to digital strategies

\section{Introduction}

Meaning and structure of oral narratives are imbedded in the lives of people. A parent's life with a baby is characterized by narrative of a parent-child communication. A teacher who cannot use narrative in pedagogy and andragogy would not be employed effectively. Oral narrative implies the use of the mouth to tell a story to an audience. A politician can only move the hearts of the voters through effective use of narrative. Manifestos, promises, and vows are invariably told to listening and/or listening audiences. As a university lecturer the author has experienced the power of oral narrative in the lecture theatre and in tutorial discussions the effectiveness of which is determined by sender-receiver mutuality and establishment of decoding of meanings.

Oral narrative is the use of word of mouth to convey a torrent of events and issues to a listening audience. In the study, the oral narratives were folktales of the Iteso. In Uganda, the Iteso numbering about 3.2 million (9.6\% of Uganda's population according to the 2002 population analysis) live mainly in the Teso sub-region in

\footnotetext{
* This study was funded in part by the Carnegie Corporation of New York and Makerere University.

Simon Peter Ongodia, Ph.D. candidate, lecturer, Department of Literature, College of Humanities and Social Sciences, Makerere University.
} 
the Districts of Amuria, Bukedea, Kaberamaido, Katakwi, Kumi, Ngora, Pallisa, Serere, Soroti, and Tororo. In Kenya the Iteso live in the Busia and Teso Districts of Western Kenya numbering about 279,000. The Iteso in Diaspora are unaccounted for in these estimates.

As most of the narratives reflected the experiences of the Iteso communities where the study was carried on, it was important to replicate the past of these people. What kind of future is worthy for a people in the contemporary world? For the study, oral narratives were the major means persons at the small communities could use to express their thoughts better. The performers used various methods of narratives; to some the historical narrative was more appealing than the mythological narration. A blend of the two forms worked well for many performers since audiences showed preference for them. Anecdotes brought in by the audience and auxiliary performers in Ateso oral narratives helped to illustrate the concerns and simplified issues for the common person to grasp.

The experiences of the researcher, as a teacher in secondary schools and then as lecturer in universities, were historical. They helped in the reflection that the life of a knowledge disseminator is characterized by both oral and written narrative. Teaching and delivering lectures involved lots of oral narration. Preparation for the teaching and lecturing sessions relied on the written accounts. Whether one used the word or other communication devices like figures and diagrams, inevitably these tools did the narrative for the learner to receive any knowledge, new or old. Much as the initial interest was to examine the pneumonic and gestural strategies used by performers of Ateso oral narratives, the consideration of the power of oral narrative as a genre took the attention of the research. The investigation led to the empathetic discovery of many forces that lay and were at interplay between the performers and their audiences. The stories being told were also affected, they metamorphosised taking in more modern language and expression.

Many philosophers and educationists (Gaarder, 1996; Bruner, 1988, 1990; Egan 1985) and literary analysts (Ong, 1982) expressed the view that the most powerful device used by human to disseminate knowledge is narrative. It builds emotive and affective images in the person (Jung, 1968) and opens doors to meaning and the extensions therein.

Narrative is the expression of ideas that are structured purposively. The account of incidents and occurrences could be linear in a chronological fashion, circular or cyclic where there is a lot of reliance on precursor incidents for proper understanding of the present ones, or meditative in a romanticized manner of fantasy and projection. Narrative is mother to other disciplines because it entails dramatic involvement, in a time space, where issues affecting humans and their environs are being expressed and analyzed with the intention of arriving at some solutions, so as to identify the roles stakeholders or players have in the business of making this world a happy place to live in.

\section{Research Questions}

The study was provoked by many questions including the following:

- What is the position of narratives of folktales in the lives of the modern Africans?

- How do philosophical and sociopolitical issues impact on the nature of oral narratives?

- How is oral narrative employed to communicate the plight of the communities?

- How do the performers evaluate the responses they receive from their audiences?

- What appraisal do audiences give the performers of oral narratives in the region?

- What kind of future do the communities aspire for? How do they envisage getting there? 
- How are the forms of narratives adjusting to the modern methods of problem-solving?

In trying investigating the place narratives of stories of a people holds in the contemporary Africa, the study appraised the remnant cultural practice of storytelling around a community evening gathering in moonlit nights. People's continual search for the truth in conflicts and crises that inflict their living in their societies was considered paramount in the quest. Human beings essentially social beings devise a way they feel effective in articulating their troubles. The power of the spoken word and acted non-verbal expression is made use of. The study was concerned with the effectiveness of this strategy in Africa of today. The key players in the dissemination of the information are the storytellers and orators. As a communication process, the performers are conscious of the feedback they generate from their audiences. In the study, their empathetic and professional points of view were evaluated in relation to successful delivery of the themes. In a reciprocal manner, the evaluation of performances by audiences had to be looked at to assess the level of impact created for positive change to be created. A further search into the tomorrow the African people look forwards to became inevitable. It was not enough to grumble about the lost glorious past in a vibrant today that could pave way for a better tomorrow.

Narratives are purposively structured and connect to a philosophy of communication. New thought patterns are provoked in the events that are being performed by characters created or cited if not masked to do so (Abrams, 1993, p. 123). What characters say and do in the stories give a narrative thought pattern about the actions and events which lead the audience to discussion, reasoning, describing, and alluding to recent events in their milieu, in order to attempt to understand their present predicament better (Knapp \& Watkins, 1994, p. 22). [Oral] [n]arrative involves coding and decoding of images which perform a cognitive process of placing the narrative plot into the introduction or beginning, the middle or the complication of issues, and the denouement or the finish (K. J. Gergen \& M. M. Gergen, 1986, p. 25). The performer will present the events in the order of importance according to the agenda of narrative. In the words of Bruner (1988), "What gives the story its unity is the manner in which plight, characters and consciousness interact to yield a structure that has a start, a development and a sense of ending” (p. 106).

\section{Methodology}

\section{Data Collection and Analysis}

This study explored the various performances of Ateso oral narratives in the Teso sub region of Uganda and Kenya. Using ethnographic methods, the study carried out in-depth interviews with 68 respondents interfaced with before and after 49 performances at the various performance sites and times from 2009 to 2013. The major stories studied included the following:

(1) Folktales 7

- Okirokuan (Troubled Life)

- Nyagilo na Eisinye (The Greedy Nyagilo)

- Apesur Akany ka Obibi (Ten Girls and the Ogre)

- Obibi ka Apese (Ogre and the Girl)

- Apesur Akany edengete Aimuria (Five Girls picking wild Grapes)

- Otoori ka Oliogom (Kite and Stock)

- Etunganan je ka Aberuke (A Man and His Wife)

(2) Trickster stories 2 
- Abaliga lo Ngora (Abaliga from Ngora)

- Opoo ka Obuin (Hare and Hyena)

(3) Fables 5

- Turukuku (A Woman and her Adolescent Girl)

- Apesur akany nu araraete Akito (The Five Girls who were collecting Firewood)

- Opowoi, Omenia, Otomei, Orisai ka Okolodong (Hare, Bat, Elephant, Leopard and Tortoise)

- Angurian na Ibaren (The Grumbling of Domestic Animals)

- Amojong kede Epege (The Old Woman and The Piglet)

(4) Mysteries 3

- Epolon ka Aberuke (The old Man and his Wife), the plight of the pumpkins-cum-sisters

- Eipone lo Abunio Atwanare Akwap (How Death came into the World)

- Aicum Akiru (Piercing Rain clouds)

(5) Legends 2

- Malinga lo Ejie (Malinga the Warrior)

- Abaliga lo Epali (The Stubborn Abaliga)

These provided studies of empathetic involvement of the stake holders in comprehending the narratives and relating their experiences to the problem-solving strategies in the socio-economic and cultural setting. There were polarized responses to the communication scenarios which were elicited in the process as were understood by the Keen's (2006) theory of narrative empathy among other theories of narratology.

Polkinghorne (1988) argues that studies should be free from positivistic research:

I find that our traditional research model, adopted from the natural sciences, is limited when applied to the study of human beings. I do not believe that the solutions of human problems will come from developing even more sophisticated and creative applications of the natural science model, but rather by developing additional, complementary approaches that are especially sensitive to the unique characteristics of human existence. (Polkinghorne, 1988, p. x)

In agreement with Bruner (1990) and Polkinghorne (1988), Minichiello, Aroni, Timewell, and Alexander (1995) emphasized that in order to understand people, “...we must discover the contents of their minds - their beliefs, wishes, feelings, desires, fears, intentions” (Minichiello et al., p. 22). According to Bruner (1990) "the symbolic systems that individuals use in constructing meaning... is deeply entrenched in culture and language. [So], we must look to people's stories to infer their intentional states and their interpretations of cultural experiences” (Bruner, 1990, p. 11). The study believed that the discovery of the richness of Ateso oral narratives as tools of mediation between culture and the world of vast insatiable needs of the humans would enhance the efforts to make a better Africa.

In the analysis, the ethnographic approach of listening to individual stories told and retold with varying modifications helped the research share meanings and concepts with the respondents. It is true to what Bruner (1990) says, "By listening to these individual stories, one can find shared meanings and shared concepts" (Bruner, 1990, p. 13). These common grounds established help us to understand the worldviews of African culture as a force to reckon with.

In analyzing the expressive language of people's narratives one opts for a qualitative rather than the quantitative examination. In quantitative approaches, a hypothesis is put forth and variables isolated. They are then acted upon to determine by measured occurrences and events if the hypothesis is true or not. In qualitative 
strategy, the model is majorly inductive because it starts with a context and ends with a greater story told. This is what Reissman (1993, p. 13) refers to as "meta-story" when describing the construction by a researcher as one built on patterns and themes of the component stories. Lancy (1999) notes that in quantitative research there "is a clear separation between the issue studied and the methodology used to conduct the study... By contrast, topic, theory and methodology are usually closely interrelated in qualitative research” (p. 3). The author chose to take the qualitative approach basing on the arguments above so as to get empathetically involved in the analyses of the new grand story being told in the Ateso oral narratives. The strategy would help the study analyze narrative thinking of both audience and performers, eliciting of thoughts, feeling and deeply held perceptions, assess the linguistic prowess of Ateso oral narratives and draw conclusions for creating a better Africa.

Data were collected using in-depth interviewing which, according to Minichiello et al. (1995), are a "conversation with a specific purpose - a conversation between a researcher and informant focusing on the informant's perception of self, life and experience, and expressed in his or her own words” (p. 60). This method helps the study delve into the treasure stores of personal experiences and concepts and the interpretations of what is going on around the people. The reserved persons can open up in the in-depth interviews and yet this may not be attained in the quantitative stratified questions and straight jacket inquiries. The author shared some of his experiences with the informants and that helped in opening them up. Sometimes, it was a reflex action of doing well to one turn. Most sessions became shared explorations of views and concepts about Ateso oral narratives. This, as Reissman (1993) says of the purpose of dialogue is to "make meaning together" (p. 55). The questionnaires distributed to some respondents provided some measurements of tendency and helped in construction of some conclusions.

The sampling of respondents was based on "information-rich case", according to Patton (1990) and Neuman (1997) from varied social setting, ethnic backgrounds and based in the rural settings and Ateso speaking communities. The author's selection was theoretically based (Patton, 1990) in that he wanted a balanced representation of respondents on social, cultural, economic, educational, religious, and gender bases. On ethical considerations, the author sought permission of local leaders and of parents for juvenile informants. Although the author had preferred that all information remain anonymous some informants expressed desire to have their names at least alluded to. Some pseudonyms were maintained especially with of those expressing "sensitive" demands. Informants were interviewed in quiet locations which they chose and away from prying eyes and ears. They had the freedom to answer or not to answer any questions. The interviews were taped and later transcribed. At times, notes were made about the interviews which helped in the interpretation of results by clarifying the perspectives and reservations of the interviewees.

As far as reliability and validity of results were concerned, the results revealed through data analysis reliability. In quantitative analysis, reliability refers to accuracy in measurement and the ability of the research to be replicated. In qualitative methods, instead of repeating measures, the researcher wants to identify a repetition of concepts, ideas, and thought patterns that can lead to new discoveries (Minichiello et al., 1995). "When we are measuring people's views, this is translated as internal and external consistency. Internal consistency refers to whether the data are plausible given all that is known about a person and an event" (Neuman, 1997, p. 368). The author interviewed retired teachers and oral performers to help him get internal consistency. These persons had repeatedly used oral narratives in their lives as teachers or as storytellers. The author had made some assumptions and they maximized the interpretative powers of each interview process, 
and according to Minichiello et al. (1995), there was rationality because the author assumed that the interviewees were familiar with oral narratives, intentionality because the study assumed that oral narratives were their trades, self-directedness as the researcher assumed that the interviewees presented authentic views from their personal experiences, truth-telling as the study treated the responses from the informants as truthful portrayal of their backgrounds and experiences.

Qualitative reliability was guaranteed by striving for external consistency. Opinion leaders in areas of the research were consulted and interviewed to ascertain the popular views about the oral narratives and performers. The researcher varied the persons interviewed, in age, sex, location, and occupation. Educational levels of individuals did not deter the interviews. The study also considered contextual factors in order to achieve reliability. Observations of several performances created triangulation to ensure that the interview fit into the overall context (Neuman, 1997, p. 368). The study tried to ascertain that the narratives were in context of the people and socio-political and economic climatic settings. There was then, "pattern matching”. Minichiello et al. (1995) suggest that qualitative researchers make a number of cultural assumptions in a pattern matching. In trying to ascertain reliability, the researcher assumes that there is an overlap among a person's beliefs, words, and ideals and his or her culture and that the subject's particular culture gives meaning to the behavior exhibited and the actions performed. In the texts and performances of this study, key concepts and catch words identified the interviewees with their cultural allegiances. The personality and office of the cultural leader of Iteso Emorimor Papa Iteso was referred to by both performers and members of the audience with ease. The respondents affirmed that it was the desire of the Iteso to have a unifying personality to help them achieve development.

In qualitative research, validity is "confidence placed in a researcher's analysis and data as accurately representing the social world in the field” (Neuman, 1997, p. 369). The researcher determined validity of the study by employing, on part time basis, some teachers, one of primary and the other of a secondary school as research assistants. They were based in the communities that speak Ateso language. They were graduates, one of them doing a master in translation studies from one Ugandan university and she was quite in touch with Ateso narratives. These research aids were adequately motivated to participate in the research, an attribute of qualitative research. Validity was also determined by involvement of other persons who were not teachers or storytellers to assess and give their input in the performances. All stakeholders, civil leaders, religious adherents, cultural heads, and politicians were interviewed to see if the research was representative of their views as well. The study was probing whether the narratives represented what was valid to the communities in their quest for answers to a number of problems. External validity could be determined when the templates of the story could be seen to apply to other situations as well. One method of conflict resolution in one narrative could be applied in another scenario. The research had to take care of all interests represented in the performances, social, economic, and cultural.

\section{Conclusion}

The study came up with a number of findings and made some conclusions with regard to Ateso oral narratives. The first property of Ateso oral narrative is the commitment which must be impressive to capture the attention of the audience. K. J. Gergen and M. M. Gergen (1986) describe a dramatic engagement as "[T]he capacity to create feelings of drama or emotion” (p. 28). For a member of an audience to listen to and watch then later on participate in an oral narrative, the empathic attachment should have been created by the 
performer and the performance. The mutual interest is established early enough between performer and audience, and has to be sustained so that the oral narrative takes grip of the audience and the varied facets of meaning are disseminated. The Teso performer was aware that appealing to some human emotion and conditions of the area helps in establishing the dramatic attachment. In some communities, the storytelling took place after cattle had been rustled by some armed persons posing as raiders. When the storyteller alluded to the incident there was unanimous support for the message being passed on condemning such robbery and arson. Iteso are agricultural and pastoral people, growing crops and keeping livestock. The Iteso in Uganda have suffered several setbacks from cattle rustling of their stock by their neighbours, particularly the Karamojong. That has made the average Etesot (an adult male native of Teso and speaker of Ateso) to divert attention to other income earning ventures like growing of crops in coping with the crises created by cattle rustling and torching of homesteads.

It was with one accord that the oral narrative and the audience-performer dramatic engagement brought the community of Iteso to terms with their situation. Similarly, in the appreciation of the fable about animals guarding a pool of living water, the performer referred the audience to the drought in the area and the members of the audience did not need a second reminder that water was precious and should not be adulterated.

In line with Keen's (2006) theory of narrative empathy, an affective link is created by the Ateso storyteller to engage the audience up to the end of the plot. Egan (1986) observes:

Stories are largely about affective matters - they are about how people feel. These feelings can either provide the motives for actions or they can provide the point and result of actions... we can see the importance of human emotions and intentions in making things meaningful. To present knowledge cut off human emotions and intentions is to reduce its affective meaning. This affective meaning, also, seems especially important in providing access to knowledge and engaging us in knowledge. (pp. 29-30)

It was portrayed in Ateso oral narratives studied that performers were aware of the power of engagement. Many strategies were employed by the storytellers to involve emotionally their audiences even though it was not plain sailing at the start. The members of the audience were effectively engaged in the narratives whenever they identified with characters and incidents in the tales. Sense could be established with the movements of the narratives and establishing links between cause and effect in the plots. With fervent commitment to understanding the story and its relevance in paving way for a better community, persons could use their imaginations to propel them to previous events and forecast the probable futures to choose from.

The second property of oral narratives is temporality, a state of existing and having some relationship with time is another property of oral narratives. Persons should identify with a specific period in time, live in it, not just exist in it and aim to make a difference to leave it better than they found it. In the dramatic engagement that the oral narratives transport their audiences, the temporality aspect is important in providing meaning to incidents and issues. In some Iteso communities where the study was conducted, members took time to relate the issues to their own circumstances. They shared their views in brainstorming sessions and came up with plausible solutions. Iteso seemed to look to the research as a possible means through which they and their views could reach the powers that be to make changes for the better. Issues of corruption cropped up in trickster stories and some fables and various communities were able to variedly assign roles to some personalities and pass judgments on them. When members of the audience knew their situation better it was possible to place meaning in the narratives they received and listened to. Storytelling in the Ateso speaking communities selected was an involving experience. Atwood (1996) says: 
When you are in the middle of a story it isn’t a story at all, but only a confusion, a dark roaring, a blindness... like a boat [being] crushed... all aboard powerless to stop it. It is only afterwards that it becomes anything like a story at all. When you are telling it, to yourself or to someone else... (pp. 345-346)

True to Atwood's statement in the Ateso oral narratives, involvement in the story is an intricate process and experience. The artists call it the "into and out of the illusionary world" engagement. We must strive to get to grips with what the characters in the story portend, the level of comprehension of their predicaments. Using the empathetic stance, the audience can place themselves in the positions of the characters and in their time and visualize the way forward. The strong motivation to have a good conclusion in the story, a better future in the real life of the members of the audience, links the oral narrative to the communities with relevance. When moral judgments were passed on immoral characters or actions in the oral narratives, there was the relieving effect: The members, at least for a time, felt some psychological relief and kept their hopes high for the actualization of their aspirations. In telling the story as Atwood points out the engagement is like a maze, a puzzle from which the audiences emerge as informed advocates of the future. The story becomes a catalyst in the transformative process in communities. Sandlos (1998) says:

The closure of a story or "how the story ends" (e.g., as a tragedy, a comedy of errors, a victory, or a defeat) is a passage of moral judgment on agents of "eventhood" within the narrative and thus provides a framework for meaning production that would not otherwise be possible given a series of disconnected events. (p. 2)

The aspirations and fears of the audience as they accepted to be part of the narratives are justified or erased as the storyteller concludes the narrative. Oral narratives work towards unity and integration of thought patterns. The narrative strives to establish a common front for the people to use for tackling their problems. Viewpoints are harmonized and extremists accommodated. Temporality makes oral narratives an excellent device for memory enhancement and easier identification of the common goal for the common good. Bruner (1990) argues that stories in a context of meaning are far more memorable than a list of dates.

Conflict resolution is the third property in oral narratives. True to most genres of literature, conflict and conflict resolution is the menu of the narratives. In folktales, there is a central conflict or complication of life and a resolution or denouement. This provides the audience with avenues of solving problems in their areas especially when similar or related issues were well articulated in the oral narratives. The Ateso tales reflected a variety of conflicts that humanity could be faced with: political, social, cultural, economic, technological, aesthetic, and psychological to name a few. The performers had to engage the audience into the problem highlights provide a development of the crises and explore strategies used for grappling with the issue. According to Egan (1988), explorations to resolve the conflict would require a variety of cognitive skills in potentially all disciplines. All faculties are required, affective, cognitive, and psychomotor. Narrative plots in Ateso oral narratives gave models which paralleled human conflicts and dilemmas and gave indicators of possible solutions.

The fourth property of oral narrative is character where roles in life situations are dressed in personalities depicting them. MacIntyre (1984) compares human life to narratives where persons have certain roles to play on stage at given times and learn the complex dynamics of our cultures.

We enter human society... with one or more imputed characters—roles into which we have been drafted and have to learn what they are in order to be able to understand how others respond to us and how our responses to them are apt to be construed. (MacIntyre, 1984, p. 216) 
He further cautions, "Deprive children of stories and you leave them anxious stutterers in their actions as well as their words" (MacIntyre, 1984, p. 216). Just as teachers should not deny their learners stories, communities should not be deprived of oral narratives by socio-cultural endowments. The people will degenerate into stutterers and desolate beings. As stories are connected to words and actions the drama should be engaging people from the start on life situation of here and now. Life is presented as fragmented actions and notions of meanings with the resultant chaos ensuing. Oral narratives in characterization in Ateso helped model and define characters to be emulated by members of Iteso communities and those to be abhorred. Oral narratives displayed intolerance in varying degrees and the models portrayed a nurturing of tolerance to be accommodated in the meaning creation process. Virtues were imparted through tolerance, establishment of trust and mutual concern for others were dressed in the characters that the oral narratives showed. Skills of survival and co-existence were interwoven in the oral narratives. The trickster tales from the Ateso stories gave fertile ground for discussion on the role of trust and tolerance in society.

Another property of oral narratives Ateso stories portrayed was voice, the right to be heard. The communities the research was carried in did not mince words in expressing their right to be heard. Many informants were saddened by the apparent denial of the right to be heard. Skepticism was shown because of disappointments realized from various empty promises of political, cultural, and religious leaderships. Audiences had to be persuaded to adopt viewpoints of the narrators. It was made possible when the audiences were made to see the stories as real to them. That is why Connor (1999) argues:

...Understanding that the storyteller—wittingly or unwittingly—selects, highlight, obscures, evades and manipulates 'the facts', is also one of the tenets underpinning critical literacy and informed social action. (p. 4)

Historical novelists and playwrights intentionally weave fiction with nonfiction in order to engage the affective and cognitive imaginations of the audience so as to activate the psychomotor domain of their faculties. Details are evoked of events of feelings that could have been lost over time. When Ngugi wa Thiong'o refers to the African struggles in his novels and plays, (for example in A Grain of Wheat (1967) or Petals of Blood (1977)) the historical fact of the political revolts against foreign rule are freely interwoven with fiction resulting in the rekindling of the fires of strong desire for a better Africa. More often than not, more truth comes out of a blend of fiction and nonfiction than a pure factual report of history. After listening to the story told, the audience members often carried on the discussion by telling related stories of their own to further illustrate the meaning they got. According to Robinson and Hawpe (1986):

Throughout the construction process, judgments and references are required at two levels: about discreet items of information and about the adequacy of the unfolding story. Selecting, comparing, inferring, arranging, and revising are activities, which we regard as cognitive strategies. (p. 116)

When the facts on the ground are blended with feeling of sympathy and empathy, the affective domain supports the cognitive one. Feelings are internalized and appreciated giving rise to positive thinking for affirmative action. The communities are able to think rationally and not emotionally as was the prevalent case in the past, for instance, after the loss of a kin to armed insurgents.

That leads to the sixth property of oral narratives, the perspective of the audience, the various ways in which each member of the listening and acting party perceive issues with a renewed outlook. Just as storytellers use various approaches to tell the same story, individual members of the audience, bearing in mind their background experiences, do understand the story in their own angle of conceptualization. In Ateso oral 
narratives, the truth in the narrative was judged subjectively and severally. The researcher recalled a simple experiment of message transmission using the rudimentary teaching aid of a line of 10 individuals spaced at five meters apart and told to convey a short message in a conveyor-belt system from source A to the neighbor. By the time the message is said out aloud by the 10th person, the amount of distortion was significant to the horror of the sender. The audience perspective is a property that oral narrators have to reckon with.

Integrative force is the seventh property of oral narratives. As we mentioned above oral narratives freely merge fiction with non-fiction sometimes in the same breath of telling. It also integrates other disciplines in the storytelling. The performance experience vied from social issues like family conflicts to cultural issues like the cultural institution of Iteso; the Iteso Cultural Union headed by His Highness the Emorimor, Papa Iteso. The same audience and performers would discuss economic and gender related issues in their communities. Science and technology often found their way into the oral narratives. In one of the folktales about mysterious girls who were got from creeping plants, Epolon ka Akeberu (The Old Man and His Wife), it was told that when their union with humans became sour, one aggrieved sister networked with her other sisters using a mobile phone and they reassembled and returned to the swamp to their family of creeping plants, abandoning their efforts to please humans. In the tale an old childless couple had been blessed by nature when they picked some creeping plants that turned out to be beautiful girls when taken home. The couple married off four of the five "daughters" to political and cultural leaders. One daughter, who was lame, refused to get married and stayed home, however, the "mother", was as ungrateful for their fortune as she was cruel. The lame girl was tortured days on end until she saw that it was enough. She called her other four sisters using a cell phone and they mournfully returned to the plant life from which they were got. Through the story told about aspects of humanity, the performer prepares the audience to comprehend the conflicts around them and seek to possible solutions to rectify the dismal conditions. Personal responsibility for actions and lack of correct actions became the topic of discussion. Ideas and facts were integrated in the narratives. In a similar way, in Angurian na Ibaren (The Grumbling of Cattle) the characters wrote a memorandum to the civic leaders demanding respect for animal rights and urging humans to desist from artificial insemination.

It is this viewpoint that Polkinghorne (1988), a narrative psychologist explains that, "the narrative scheme serves as a lens through which the apparently independent and disconnected elements of existence are seen as parts of a whole” (Polkinghorne, 1988, p. 36). It follows that any oral narrative provides the opportunity for members to integrate their experiences and existences of other beings in the bid of subduing the world for the good of humanity.

The eighth property of oral narrative is cultural mediation. In many narratives that the study examined, the performers ended the plot with reference to the cultural institution of Iteso. A storyteller extricated the fictional narrative by saying that the cultural leader of Iteso (who was not mentioned anywhere in the narrative, but assumed to have eyes and ears everywhere) was concerned about the crises displayed in the narrative. This appeal for cultural unity was seen by many performers as a tool for harnessing constructive energies for a better Africa. Bruner (1990) indicates that one of the properties of narrative is its ability to "forge links between the exceptional and the ordinary” (Bruner, 1990, p. 47). He continues to state that the stories of a culture perpetuate its morals and traditions, but the conflict and resolution structure of a narrative allow for negotiated meaning when there is a conflict, when intent must be considered.

The Ateso oral narratives invariably alluded to facets of culture. The story of the creeping plants turned beautiful girls alludes to the cultural cord of Iteso who identify themselves with the creeping plant, emuria, 
tough, and resilient to all weather. Narrative "mediates between the canonical world of culture and the more idiosyncratic world of beliefs, desires and hopes” (Bruner, 1990, p. 52). Oral narratives essentially provide avenues for moral decision-making and conflict resolution. The performers gear their oral tales to suitable endings that support the people's cultural values, ethos, attitudes, feelings, and norms. These values play significant roles in helping the people make up their minds about certain crises. They prioritize the values highlighted and base their rationalized conclusions on them. The oral narratives make audiences foresee an outcome of some set of actions while the stories they share related to the narrative enables them engage integrated support from one another. The power to identify the nature of the problem, issue, or conflict is given, cultural values are explained, and the process of value prioritization is set in motion. The Iteso audience was able to predict possible outcomes of a given series of occurrences and then support a feasible resolution to the crises in given circumstances.

A renewed perspective is the ninth property of narrative. The process that the beginning of a storytelling session ignites continues the flame of inquiry into the meaning of life and the crux of conflicts pervading human communities. People want the truth about their story however gloomy it might be. Social scientists call this identity a placement of a person to a milieu. In the study, it was not uncommon for Iteso audiences getting up in arms against adulteration of their folktales. Performers and their auxiliaries were often challenged when communities thought that their narrative was blatant distortion of facts. Violence was viewed in varying angles of the characters portrayed in the tales. The experience of oral narrative gave some people opportunities to journey into the self, own what they can, and identify with some aspects of the past that they know worked well. Reconciliation is seen as a tool for reconstruction of African societies. In the oral narratives, the irreconcilable characters are ejected from society and their state of being outcasts is judged as punitive.

The tenth property of oral narrative is reflection when the meaning obtained and the renewed perspective arrived at empowers the individuals to give better informed meanings to their predicaments. MacIntyre (1984) suggests that narrative is the pathway to meaning, because our lives are a narrative. The power of narrative is that it reflects our own life space. This effect is heightened by the overlap of life narratives; the interplay of generations that gives us clues to interpreting our own events (MacIntyre, 1984, p. 212). In the reflection stage, the Iteso audiences and performers could see new possibilities of solving what had looked insurmountable tasks. But this, they concurred, required action and not apathy. Bruner (1990) says:

When we enter human life, it is as if we walk on stage into a play whose enactment is already in process-a play whose somewhat open plot determines what parts we may play and toward what denouements we may be heading. (p. 34)

In the reflection phase, the oral narrative gives the audience and performers certain viewpoints open to them. They feel privileged to have enough sense to redesign their destiny using the knowledge obtained from the storytelling experience. As they each view their lives as personal narratives, they get a better view of self which helps in undertaking the journey of life further on. The brainstorming sessions that followed some narratives showed that the participants had come to terms with their realities and were not projecting blame to other persons or bodies but were determined to harness resources in their reach for a better Africa. This is what K. J. Gergen and M. M. Gergen (1982) refer to as the healing power of narratives when they argue that narrative becomes a powerful psychotherapy tool when patients feel empowered to identify their conflict and look towards possible positive resolutions (K. J. Gergen \& M. M. Gergen, 1982, p. 27). 


\section{Recommendations}

The study recommends that a new Africa can be realized with interactions and connections being revived through oral narratives of the people of Africa. Oral narrative as a genre gives the personal, individual, and communal concerns a voice, a projection that reflects the perception of the actors in a given scenario. It points out that there is the concern of all who must play their roles in the circumstances to pave way for the better future. Oral narratives become the cultural mediator and umpire for the norms of the community. Through oral narratives communities adopt new attitudes and outlooks to issues that could have been insurmountable for an individual. The Iteso find that they can forgive one another and reconcile with their hostile neighbors as they look to the future. The elders and the youth can live in harmony in spite of the previous animosity that might have existed in the socio-cultural revolutions.

\section{Narrative Language for Development}

The study examines the relationship between narrative language and development. Following what the structuralist, Chomsky $(1965,1968)$ believed that there was an innate ability of individual to learn and develop language in his language acquisition device, Bruner (1990) claims that "innate syntactic language" is modified with social interactions and that "rules can only be learned instrumentally" (p. 70). When an oral narrative is performed there may be cases of innate readiness for the meanings to be inferred by the ability to form prelinguistic appreciation of context. Bruner's (1990) views agree with Polkinghorne who says that "the more accepted position is that narrative structure although dependent on basic human capacities, are acquired by abstractions from experiences" (Polkinghorne, 1988, pp. 112-113). The generalizations conceived begin as the narrative unfolds and is helped by precursor events in the interpreters' minds. Word meanings get generalized as members of the audience play with the verbal dexterity and the acquired meaning is shared by the speech community. Bruner (1990) claims that humans have the will to communicate and "the push to construct narrative determines the order of priority in which grammatical forms are mastered” (Bruner, 1990, p. 71).

The study about constructing knowledge using narrative was done way back at the times of the educationist Montessori (1912) who notes that children at a remarkably young age are making sense of their worlds through language. According to her, "dictorium" is the use of language for intellectual growth. Spoken language (oral narrative so to say) "develops through the exercise of its mechanisms and is enriched by perceptions and dictorium that develops with the mind and is enriched by intellectual culture" (Montessori, 1912, 1988, pp. 247-248). This view is true of oral narratives in African folklore. In the arguments about the power of oral narratives in fostering development, the study notes that communities need to develop communicative strategies that are in resonance with narratives. Westby (1991) says:

Developmentally, narrative is the first language form that requires the speaker to produce an extended monologue rather than an interactive dialogue. In relating or listening to a narrative, the speaker and listener act as spectators rather than participants. As spectators, the speaker and listener reflect on experiences, whereas as participants, they use language to get things done and make changes in the current situation. (p. 340)

What Westby says is in line with the thesis of the study. Ateso oral narratives can be used effectively by Iteso to foster development. Africa can solve her problems using actively narrative. Polkinghorne (1988) contends that:

For human existence, linguistic forms are paramount, for they filter and organize information from the physical and cultural realms and transform it into the meanings that make up human knowledge and experience. On the basis of this 
constructed experience, we understand ourselves and the world, and we make decisions and plans regarding how we will act. (Polkinghorne, 1988, p. 158)

\section{Oracy as a Sharpening of Literacy Prospects}

In one of the Ateso folktales, Angurian na Ibaren (The Grumbling of Cattle), the storyteller dramatizes how the characters wrote a letter to the government to express their grievances. That is utilizing literacy as a tool of expression. Oracy gives rise to literacy, the orate characters prove themselves to be literate. The more orate our people become the more chances of their becoming well-read and knowledgeable. Goodman (1986) says:

Language is language only when it is whole. Whole texts, connected discourse in the context of some speech or literacy event, are really the minimal functional unit, barest whole that makes sense. When [we] look at words, phrases, sentences, [we] do so always in the context of the whole, real language texts that are part of real language experiences of people. (pp. 27-28).

Audiences get immersed into narratives that the power of literacy is sharpened. Fox (1997) illustrates the immersion process in narrative saying that, "when we develop literacy we should be reading aloud daily" (p. 123). She was emphasizing two points: selecting good literature and daily reading. What was being recommended for a classroom teacher applies in oral narratives where the performer is teacher and the audience is the students. Oral narratives assist developing the literacy skills. Cambourne (1988) uses the parallel of oral language to emphasize that making errors is not only normal, it is "absolutely essential to the whole process" of learning to read and write (Cambourne, 1988, p. 67). In learning to speak we go through a series of successive approximations. In learning to read and write, we should be allowed to do this as well in a judgment free, safe and secure environment. The study explored the power of oral narrative in enhancing an understanding of a given language. This involved getting to grips with the journeys of personalities in the stories, linking them to individual journeys of members of the audience and their communities in line with their culture. Oral narratives help enrich the understanding of a culture and way of life of a people.

The researcher interviewed performers and members of the audiences to determine strategies; they felt plausible in their given environment to have things change for the better. The researcher noted that their understanding of their predicaments ran deeper than the language they were using could express. Nonetheless, they opted for the oral narrative medium of expression as relieving for both the participants and the stakeholders. Storytelling reflects life's journey by affording members of the audience opportunities to explore their personal narratives in their social setting. The ability to understand life experiences meaningfully is enhanced. All human life is a cyclic mirror: we are born, we grow, we learn, we work, we play, we face conflicts, and have to make choices, we relate with other human beings, and we propagate and die, to let others continue the cycle. In spite of these repetitive phenomena, each individual has a role to play in the cosmos. Oral narratives provide imagery for self exploration using metaphors of life. The ability to process the images using the cognitive and the affective domains help the understanding of the patterns and rhythm of the person, emotionally, cognitively, and socially.

Oral narratives help in noting the importance of narrative as well as paradigmatic thought patterns through the provision of allegory, image, and metaphor. Bruner (1988) says, "Narrative thinking, a good story, convinces us of the likeliness of the events occurring or the character existing. This is in contrast to "the 'well-informed argument' of paradigmatic thinking which aims to convince us of truth” (p. 99). This leads to 
the cause and effect thought patterning, which Robinson and Hawpe (1986) say "are attempts to organize and give meaning to human experience, to explain and guide problem solving” (p. 114). Listening to the free conversations of the audience members and performers after performances, the researcher observed that both the paradigmatic and narrative thought patterns were being used concurrently. Some people used logico-scientific reasoning to design a structure of plot the narrative should have taken, and immersed themselves into the action of the story, took on some role(s) and explained what he or she could have done in the circumstances. The word which is the productive creation of human for expression is related to many aspects. Ong (1982) comments on oral recitation, "The oral word... never exists in a simply verbal context, as a written word does. Spoken words are always modifications of a total, existential situation which always engages the body” (p. 67). When literacy is developed the person has to provide more to make the word lucid and clear to the reader.

\section{Reading the Signs of Time, Traditions, and Festivals}

We experience the signs of time through daily and weekly patterns, seasonal patterns and by a realization of the past, present, and the future we want in Africa. The linear and circular stories in Ateso oral narratives celebrate traditions, customs, and festivals. Celebrations mark passage of time in which connect to the people's past, birthdays, marriage anniversaries, funeral rites and other rites of passage. Traditions and cultural festivals bring families together to celebrate aspects of their existence. Mock (1999) says, "The sense of belonging engendered by their participation in family cultural traditions make our active support important... Traditions and stories can make the present more meaningful, the past more believable, and the future more possible” (p. 34). Hence, the celebration of narratives in Ateso oral folktales help the communities to understand the present of their existence, believing in the past treasures and norms and to forge ahead for a bright future for people of Africa. In traditional oral cultures, thought and memory are related to sound. If a story was forgotten by a tribe, it was lost forever. "For this reason, oral cultures have exploited language to aid memory" (Egan, 1997, p. 58). Mnemonic patterns include the phrases and sayings that are echoed from one occasion to another. The repetition of words and ideas, alliterations, and assonances (Ong, 1982; Egan, 2000) help in memory retention. Ong (1982) points out that in oral cultures, it is important for there to be a lapse of time before a story is retold since this gives the listener time to formulate personal patterns that would enable him or her to remember the tale in an internalized version. "Part of this memory process involved identifying 'standard thematic settings' (the assembly, the meal, the duel, the hero's helper, and so on), in proverbs which are constantly heard by everyone so that they come to mind readily and which themselves are patterned for retention and ready recall" (Ong, 1982, p. 34). The power of story can be used for communities of oral societies to aid memory as "lore coded within a story structure... much easier to preserve. They could orient hearers' emotions to their contents" (Egan, 1997, p. 62).

When stories are told, the listeners share in the storied experiences of others with whom they feel a connection which Keen (2006) refers to as "speculation about human empathy's positive consequences” (p. 207). The speculation and connection influence the choices that contribute to the uniqueness of individuals. Personal journey choices can also be affected by an awareness of endowments and interests that constitute individual uniqueness and personal traits. The Focused Group Discussions held in the study revealed that people were encouraged to explore their personal narratives and discover their own voices and viewpoints to guide them in the life's journey. The speculation can be used as integrating force when narrative helps person 
find the inner authentic voice to experience transformation through effecting psychological and spiritual development. Once one has recognized a journey, he or she engages respect for other people's journeys are enhanced to assist in getting deeper meaning. This inquiry involves envisaging a goal related to personal change and coping with obstacles on the pathways to achieving greater ideals. People develop creativity as an outward expression of inner balance which involves discovering universal truths and values and relating these to one's life through interweaving archetypes and transcend cultural limitations.

\section{Dialogue and Self Discovery}

In the tale of Okirokuan (Troubled Life) fate and fatalism pave way for the down trodden. The protagonist is an adopted into a family with a benevolent foster father but an evil step mother. As fate would have it, this male Cinderella turns out to be the most intelligent and brave man who is liked by all human beings and wild animals alike. He establishes his home in the middle of a virgin forest and lives happily with his wife. The story is agro-forested in setting and opens avenues of untrodden paths for problem-solving strategies. Humans are made to see virgin forests that are surviving as fertile ground for agriculture, the backbone of their community's economy. The forests house the fauna and floras that are friendly to humanity are harnessed well.

\section{Change Beginning With Self}

In the story Amojong ka Epege (The Old Woman and the Pig) threats and fear are used to solicit support and adherence from parties that are selfish and conceited. The wayward leader is made to do the common good. Sanctions imposed today reflect the coercive nature of humanity where the wayward brother or sister is brought back in line with humanity by the threat of pain inflicting steps is posted on the menu. Change is pivoted as a personal journey into the self, a re-examination of one's role in the development process. It abhors the apathy and laziness, the sins of omission and commission.

\section{Conflict Resolution Strategies Identified}

In the Ateso oral narratives, each story had a crisis it portrayed. The members of the audiences exploited the opportunities to examine the strategies the fictitious characters took in attempting to resolve standing issues. Community awareness campaigns were being exercised at will. Government organs and other well wishers take heed from the stories and the avenues that were provided in the narratives and when there were programs like eradication of poverty and alleviation of the standards of living of the communities, the stakeholders were better informed on strategies that were friendly to the particular society. In bringing economic, social and health issues to the attention of the societies the players would be better informed on the plausible strategies to use.

Storytelling also helped communities identify problems that afflicted them. Slavery to an unidentified issue is worse that knowledge of the existence of the crises. Problem identification strategies were given by the oral narratives in varied proportions. This helped the communities to own up some issues and look for solutions to them in their efforts to seek a better tomorrow.

As one story showed, it was time communities realized that they lived in a global setting where the physical and political frontiers did not play a big role. Networking was a solution that had come with the digital era and had to be made use of at all costs. That would ensure that linkages and affiliations were rooted in the Africa of today and tomorrow. Just like most oral narratives alluded to associations and connectivity, Epolon ka Aberuke (The Old Man and His Wife) where characters used mobile phones to network, the digital facilities ought to be used in getting solutions to the kaleidoscope of social issues. 


\section{Implications for Further Research}

In the seven years the researcher spent living with various communities of Ateso speakers, he saw that there were many unwritten tales being passed on by word of mouth. The stories had a number of modifications as far as the elderly members of audiences could recall. This meant that the authentic orthodox stories were being lost slowly. This source should be tapped and made usefully available for the present Africa.

In a similar way, a number of conflict resolution avenues were being suggested if not alluded to. As communities develop, a number of divergences emerge and new methods of declarations need to be exploited to enable humans live meaningfully in harmony.

Most of the concerns of the communities were about survival. Now that there was relative political stability established in the region, the major threat to their livelihood was the food basket. Food security in the region should be studied and plausible means devised to ensure that there is food for all, starting with a sensitization through accessible oral narratives.

\section{References}

Abrams, M. H. (1993). A glossary of literary terms (6th ed.). Sydney: Harcourt Brace College Publishers.

Atwood, M. (1996). Alias Grace. London: Virago.

Bruner, J. (1988). Two models of thought. In N. Mercer (Ed.), Language and literacy from an educational perspective (pp. 100-109). Philadelphia: Open University Press.

Bruner, J. (1990). Acts of meaning. Cambridge, M.A.: Harvard University Press.

Cambourne, B. (1988). The whole story: Natural learning and the acquisition of literacy in the classroom. Sydney, NSW: Aston Scholastic.

Campbell, J., \& Moyers, B. (1988). The power of myth. Sydney, NSW: Doubleday.

Chomsky, N. (1965). Aspects of the theory of syntax. Cambridge, M.A.: The M.I.T. Press.

Chomsky, N. (1968, 1972). Language and mind. N.Y.: Harcourt Brace Jovanovich, Inc..

Connor, J. (1999). Links with literary texts. Marrickville, NSW: Primary English Teachers Association.

Egan, K. (1985). Teaching as storytelling: A non-mechanistic approach to planning teaching. Journal of Curriculum Studies, 17(4), 397-406.

Egan, K. (1986). Teaching as storytelling: An alternative approach to teaching and curriculum in the elementary school. Chicago: The University of Chicago Press.

Egan, K. (1997). The educated mind: How cognitive tools shape our understanding. Chicago: The University of Chicago Press.

Egan, K. (2000). Memory, imagination and learning: Connected by the story. Retrieved October. 4, 2013, from http://www.educ.sfu.ca/kegan/MemoryIm.html

Fox, M. (1997). Towards a personal theory of whole language: A teacher-researcher-writer reflects. ALEA: The Australian Journal of Language and Literacy, 20(2), 122-130.

Gaarder, J. (1996). Sophie's world. London: Phoenix House.

Gardner, H. (1983). Frames of mind: The theory of multiple intelligences. N.Y.: Basic.

Gardner, H. (1993). Multiple intelligences: Theory in practice. N.Y.: Basic.

Gardner, H., \& Winner, E. (1979). The development of metaphoric competence: Implications for humanistic disciplines. In S. Sacks (Ed.), On metaphor. Chicago: University of Chicago Press.

Gergen, K. J., \& Gergen, M. M. (1986). Narrative form and the construction of psychological science. In T. R. Sarbin (Ed.), Narrative psychology: The storied nature of human conduct (pp. 22-44). N.Y.: Praeger.

Goodman, K. (1986). What's whole in whole language. Ontario: Scholastic Educational.

Jung, C. G. (1968). Approaching the unconscious. In C. G. Jung (Ed.), Man and his symbols (pp. 1-94). N.Y.: Dell Publishing Co..

Keen, S. (2006). A theory of narrative empathy. Retrieved from http://muse.jhu.edu/journals/narrative/v014/14.3keen.pdf

Kelly, M. (2000). Storytelling: Using folk tales to inspire the fire within. Proceedings from ALEA State Literacy Conference. Perth, W. A.

Knapp, P., \& Watkins, M. (1994). Context-Text -Grammar. Broadway, NSW: Text Publications. 
Lancy, D. R. (1999). Qualitative research in education (pp. 1-32). N.Y.: Longman.

MacIntyre, A. (1984). After virtue: A study in moral theory (2nd ed.). Notre Dame, Indiana: University of Notre Dame Press.

Minichiello, V., Aroni, R., Timewell, E., \& Alexander, L. (1995). In-depth interviewing. Melbourne: Longman Australia Pty. Ltd..

Mock, S. (1999). Young children in time. Montessori Life, 11(4), 34-36.

Montessori, M. (1912). The Montessori method. London: William Heinemann.

Montessori, M. (1964). Spontaneous activity in education. Cambridge, M.A.: Robert Bentley, Inc..

Montessori, M. (1988). The discovery of the child. Oxford: Clio Press.

Neuman, W. L. (1997). Social research methods: Qualitative and quantitative approaches. Sydney: Allyn and Bacon.

Ngugi wa Thiong'o. (1967). A grain of wheat. London: Heinemann.

Ngugi wa Thiong'o. (1977). Petals of blood. London: Heinemann.

Ong, W. J. (1982). Orality and literacy: The technologizing the word. London: TJ. Press, Ltd..

Patton, M. Q. (1990). Qualitative evaluation and research methods (2nd ed.). London: Sage Publications.

Polkinghorne, D. E. (1988). Narrative knowing and human sciences. Albany: State University of New York Press.

Reissman, C. K. (1993). Narrative analysis: Qualitative Research Methods Series 30. London: Sage Publications.

Robinson, J. A., \& Hawpe, L. (1986). Narrative thinking as heuristic process. In T. Sarbin (Ed.), Narrative psychology: The storied nature of human conduct (pp. 111-125). N.Y.: Praeger.

Sandlos, J. (1998). The storied curriculum: Oral narrative, ethics and environmental education. Journal of Environmental Education, 30(1), 5-10.

Sarbin, T. R. (1986). The narrative as a root metaphor in psychology. In T. R. Sarbin (Ed.), Narrative psychology: The storied nature of human conduct (pp. 3-21). N.Y.: Praeger.

Steiner, R. (1923/1996). The child's changing consciousness as the basis of pedagogical practice. Hudson, N.Y.: Anthroposophic Press.

Taylor, F. (1911). The principles of scientific management. N.Y.: Harper.

Uganda Population and Housing Census. (2002). Analytical Report (Uganda Bureau of Statistics) March 2005.

Westby, C. (1991). Learning to talk-Talking to learn: Oral-literate language differences. In C. S. Simon (Ed.), Communication skills and classroom success (pp. 181-218). San Diego, CA: College-Hill. 